Relato de experiência

\author{
Fábio de Oliveira \\ (iD) https://orcid.org/0000-0002-0109-1413 \\ Leny Sato ${ }^{a}$ \\ (iD) https://orcid.org/0000-0002-4114-097X \\ Carla Catarine Moura Queiroz ${ }^{\mathrm{a}}$ \\ (iD) https://orcid.org/0000-0002-8086-4073 \\ Denise Harumi Sakô ${ }^{\mathrm{a}}$ \\ (iD) https://orcid.org/0000-0002-2197-0685 \\ Flávia Manuella Uchôa de Oliveira ${ }^{a}$ \\ (iD) https://orcid.org/0000-0002-6847-8436 \\ Juliano Almeida Bastos ${ }^{\mathrm{a}}$ \\ (iD) https://orcid.org/0000-0002-8905-0543 \\ Cris Fernández Andradab \\ (iD) https://orcid.org/0000-0002-4939-8924 \\ Samir Perez Mortadac \\ (iD) https://orcid.org/0000-0003-0338-1075
}

a Universidade de São Paulo, Instituto de Psicologia, Departamento de Psicologia Social e do Trabalho. São Paulo, SP, Brasil.

b Pontifícia Universidade Católica de São Paulo. São Paulo, SP, Brasil.

c Instituto Federal de Educação, Ciência e Tecnologia da Bahia. Salvador, BA, Brasil.

Contato:

Fábio de Oliveira

E-mail:

fabioliv@usp.br

Os autores declaram que o estudo não foi subvencionado e que não há conflitos de interesses.

Os autores informam que o trabalho não é baseado em tese ou dissertação e não foi apresentado em eventos científicos.

\section{Pesquisa-intervenção participativa com trabalhadores da Unidade de Manutenção de uma universidade pública: precarização, memória e resistência}

\author{
Participatory research and intervention with workers of the \\ maintenance unit of a public university: precariousness, \\ memory and resistance
}

\section{Resumo}

Este relato descreve a assessoria sindical em Psicologia Social do Trabalho e em Saúde do Trabalhador junto a funcionários/as da Unidade de Manutenção de uma universidade pública brasileira. Após uma greve por melhorias nas condições de trabalho e por medidas de combate ao assédio moral, foi formado um grupo de trabalhadores e pesquisadores (estudantes de graduação, de pósgraduação, pesquisadores de pós-doutoramento e docentes) que desenvolveu um projeto nos moldes de uma pesquisa-intervenção participativa. Ao longo de mais de dois anos, foram desenvolvidas as seguintes atividades: participação dos pesquisadores nas reuniões organizadas pelos trabalhadores; visitas aos locais de trabalho; fomento das discussões sobre assédio moral, condições e organização do trabalho; realização de entrevistas individuais e em grupo; atendimentos clínicos. Essas atividades permitiram intervir na formação, no acolhimento ao sofrimento relacionado às situações de violência, no resgate do valor do trabalho e dos saberes dos trabalhadores. Foi possível reconhecer que as instabilidades e as precariedades do trabalho têm sido fonte de sofrimento e de conflitos. Constatamos que os trabalhadores são portadores de rico saber sobre a universidade, sobre o seu próprio trabalho e sobre as mudanças em curso, bem como sobre as consequências do acelerado avanço da terceirização e do desmonte de diversos setores da universidade.

Palavras-chave: psicologia social do trabalho; saúde do trabalhador; precarização do trabalho; universidade pública; pesquisa participativa.

\begin{abstract}
This report aims at describing the union assistance, based on social psychology of work and worker's health, provided for the maintenance workers of a Brazilian public university. After a strike for improvements in working conditions and measures to combat moral harassment, a group of workers and researchers (undergraduate, graduate, post-doctoral researchers and professors) was formed and a project based on participatory intervention research was built up. Throughout two years, the following activities were developed: researchers participation in the meetings organized by workers; workplaces visits; discussions on moral harassment, work conditions and organization; individual and group interviews; clinical care. These activities allowed to intervene in the workers' training and in the assistance provided to minimize the suffering caused by violence at work, as well as to rescue both the value of work and workers' knowledge. It was possible to recognize that the work instabilities and precariousness have been source of suffering and conflicts. We found that workers have a valuable knowledge about the university, their own work and the changes in course, as well as about the consequences of the accelerated advancement of outsourcing and the dismantling of various university sectors.
\end{abstract}

Keywords: social psychology of work; occupational health; precariousness of work; public university; participatory research. 


\section{Introdução}

Este artigo relata o percurso de uma intervenção em saúde do trabalhador que consistiu em assessoria sindical ocorrida ao longo de mais de dois anos junto a trabalhadores da Unidade de Manutenção de uma universidade pública brasileira. O caminho percorrido ao lado dos trabalhadores teve vários focos no decorrer do processo de pesquisa-intervenção participativa ${ }^{1,2}$, começando com a assessoria no encaminhamento de denúncias de assédio moral no trabalho, passando por discussões sobre condições de trabalho, organização do trabalho, precarização e terceirização, e desembocando finalmente numa tentativa de resgatar a memória de trabalho como forma de resistência ao desmonte daquela unidade.

Esta experiência reflete as transformações pelas quais o mundo do trabalho vem passando nas últimas décadas e que também afetam o setor público. Notadamente, onde se desenvolvem os serviços públicos tidos como bens sociais, como educação e saúde, as consequências são sentidas pelos trabalhadores que, comprometidos com o exercício da função pública, se veem impedidos de realizar seu trabalho com base em uma ética do bem comum ${ }^{3}$ em virtude da gestão do trabalho que tem sido imposta.

Ancoradas nos princípios neoliberais em voga desde os anos $1990^{4}$, as mudanças na gestão foram transplantadas das empresas para os serviços públicos, desvirtuando sua natureza e função com modelos orientados para a produção e a comercialização. Em nome de uma suposta eficiência e de melhorias na qualidade ${ }^{5,6}$, tais princípios, dentre os quais destacamos a flexibilização, têm sido implantados indiscriminadamente e vêm abrindo, progressivamente, terreno para a precarização do trabalho nos serviços públicos brasileiros. "Precarização" compreendida como a piora geral das condições de trabalho e de vida decorrente da ruptura do modelo taylorista-fordista, da busca pela redução de custos de produção e pelo retorno às ideias liberais, principalmente a de estado mínimo, o que engloba a fragilização dos vínculos de trabalho, a perda de direitos, o enfraquecimento das políticas de proteção social, a degradação dos ambientes de trabalho, a intensificação das formas de exploração, a desarticulação política dos trabalhadores.

Chauî $^{7-9}$, ao analisar a implantação dessas transformações nas universidades públicas, aponta que a qualidade passa a ser medida pela produtividade, que se traduz em volume, agilidade e baixo custo. A autora observa que "a pergunta pela produtividade não indaga o que se produz, como se produz, para que ou para quem se produz, [...] opera-se uma inversão tipicamente ideológica da qualidade em quantidade"7 (p. 2).
Nessa direção, ressalta-se o avanço do processo de terceirização dos serviços universitários considerados "auxiliares" - limpeza, vigilância, transporte, manutenção ${ }^{10}-$, que passam a ser realizados por empresas contratadas, e não mais por funcionários dos serviços públicos, e a crescente precarização do trabalho que caracteriza esse processo ${ }^{11-13}$. Das dimensões da precarização decorrente da terceirização, conforme apontam Franco, Druck e SeligmannSilva ${ }^{14}$ e Druck ${ }^{5,6}$, destacam-se as que se relacionam à fragmentação da classe trabalhadora (fragilização da organização coletiva) e à piora das condições de segurança e saúde - aspectos que dialogam com as situações de trabalho descritas.

\section{Pressupostos teóricos e percurso metodológico}

A intervenção orientou-se por princípios do pensamento de Paulo Freire, pois tivemos por objetivo a transformação e a resolução de problemas por meio de formas coletivas de ação. Neste tipo de prática política de compromisso popular, desloca-se a pergunta do que é ciência, estimulando-se interrogações históricas sobre como, por que e a quem serve a ciência ${ }^{15}$. Tratamos, como afirma Brandão ${ }^{15}$, de "perguntas de pessoas reais", não de categorias abstratas de "objetos" atreladas a um conhecimento "científico" ou "técnico" (p. 11).

Fomos chamados por trabalhadores em situações concretas de assédio moral e de intensa precarização das condições de trabalho. Foram eles que, ao pensarem em sua realidade, e com o objetivo de transformá-la, utilizaram-se dos conhecimentos científicos e técnicos críticos produzidos pelas psicologias. No limite, já havia nesse chamado sujeitos, e não "objetos de pesquisa", praticando o ato de conhecer e utilizando-se deste conhecimento para a mudança de sua realidade. Assim, foram formados dois grupos: "grupo acadêmico" (composto por estudantes, pesquisadores e docentes) e "grupo do projeto" (composto pelo "grupo acadêmico" e pelos representantes dos trabalhadores da Unidade de Manutenção).

Elencamos pontos específicos de nossas ações, ligados a esta "opção libertadora" de pesquisa de que fala Paulo Freire ${ }^{16}$. O primeiro ponto trata da importância do conhecimento e da participação dos trabalhadores em todos os momentos do processo de pesquisa-intervenção participativa. Não houve divisão entre pessoas "pesquisadas" e "pesquisadoras", as delimitações de nossas ações foram pensadas junto dos trabalhadores. A relação horizontal construída é um aspecto central e precioso da intervenção.

O segundo ponto relaciona-se à "porosidade das fronteiras entre pesquisa, intervenção e formação"1. 
Na perspectiva libertadora, conceber e praticar a pesquisa é, para o pesquisador, facilitar o conhecimento da realidade pelos grupos. Quanto mais estes grupos conhecem sobre si e sobre sua realidade, tanto mais podem superar conhecimentos anteriores ${ }^{16}$.

Pelo dinamismo da pesquisa e do diálogo construídos, temos o terceiro ponto: a construção da metodologia por meio das demandas ao longo do processo. O método não poderia ser pensado de antemão, pois foi pela convivência com os trabalhadores que pudemos entender quais as ações necessárias a cada momento, o que Pais ${ }^{17}$ chama de "fazer artesanal da pesquisa".

Finalmente, o quarto ponto foi a formação de uma "comunidade ampliada de pesquisa e intervenção"18. Esse dispositivo tem por objetivo favorecer a construção de espaços de diálogo e de confrontação entre diferentes saberes, ampliando outros regimes de produção de conhecimento que reúnem pesquisadores profissionais e trabalhadores numa relação dinâmica e cooperativa na análise de situações de trabalho ${ }^{19}$.

Em síntese, as ações de intervenção realizadas foram: assessoria à denúncia e combate ao assédio moral; atendimento psicológico em caráter de emergência; construção da memória de trabalho; e participação em atividades dos trabalhadores. Essas atividades tiveram início em abril de 2016, com a elaboração de um parecer. Elas aconteceram com maior intensidade ao longo de 2016 e de todo o ano de 2017. Atualmente, a equipe trabalha na redação de um material escrito que registra a experiência desses trabalhadores.

Os caminhos trilhados resultaram de um processo em que alguns aspectos se impuseram delineando as ações: os problemas, as circunstâncias, o que era necessário e o que era possível. Construímos uma "intervenção pesquisante", pois embora o foco inicial fosse a intervenção, ao longo do projeto mantivemos uma postura investigativa, atitude imprescindível para que a intervenção ocorresse.

A dinâmica das relações políticas e as seguidas mudanças no trabalho impostas pela gerência, que apontavam para um processo de desmonte da unidade, exigiram que o processo de pesquisa-intervenção participativa mantivesse um contínuo planejamento-replanejamento. Assim, não foram poucas as ocasiões em que o "grupo acadêmico" precisou rever suas intenções. Nesse processo, foi essencial a participação ativa de representantes sindicais de base, que, além do papel político, demonstraram conhecer profundamente a realidade e o cotidiano daquele trabalho, trazendo contribuições relevantes em termos de método, de procedimentos e de alvos de intervenção-pesquisa. Situando-se em plena turbulência da realidade social, os recursos e as técnicas utilizadas para desenvolver o trabalho foram os disponíveis e viáveis, características que já foram consideradas por cientistas sociais da Escola de Chicago ${ }^{20,21}$.

\section{Resultados}

Os trabalhadores que demandaram a intervenção estão alocados na Unidade de Manutenção, responsável pela infraestrutura das outras unidades da universidade. Ela vem sofrendo redução do quadro de pessoal há algum tempo: na década de 1990, contabilizavam-se cerca de 1.200 trabalhadores, enquanto em 2016 contavam-se cerca de 260 trabalhadores. A maioria é composta por homens com funções de nível básico e médio que atuam em atividades operacionais de manutenção (construção civil, jardinagem, marcenaria etc.).

Por ser uma unidade de prestação de serviços, os locais de trabalho são diversos. Outra característica relevante é o fato do trabalho dos servidores ser realizado paralelamente por funcionários terceirizados: esses dois grupos convivem cotidianamente, apesar de não manterem uma relação tão próxima. Haveria muito a dizer sobre essa relação, mas esse assunto ficará para uma eventual próxima publicação.

\section{Assédio moral e greve}

Partimos da solicitação de representantes sindicais de base a dois autores deste artigo para que elaborassem um parecer sobre vários casos de assédio moral contra trabalhadores da Unidade. O parecer serviu de base para a abertura de um processo administrativo interno à universidade para investigar os casos. Mais recentemente tivemos notícias sobre o resultado dessa sindicância. Não nos cabe neste momento julgar as decisões tomadas, mas apenas indicar que a judicialização dos casos de assédio e a individualização de suas causas fazem desvanecer seus determinantes organizacionais ${ }^{22}$.

Diante da gravidade da violência constatada, oferecemos apoio aos trabalhadores no enfrentamento das situações produtoras do assédio moral e das repercussões psicológicas da violência sofrida. $\mathrm{O}$ assédio moral se caracterizava por práticas de gestão marcadas pela violência e pela perseguição mais intensa contra alguns trabalhadores - o que incluía situações de misoginia e homofobia, entre outras. Esses casos causaram tanta comoção que motivaram a decretação de greve na Unidade. Uma greve histórica, que conseguiu mobilizar a grande maioria dos trabalhadores, suspensa apenas quando algumas condições para amenizar os problemas foram conquistadas. 
Em conversas com os trabalhadores, foi ficando explícito para eles e para nós como a falta de funcionários, as políticas de gestão da universidade e o modo de funcionamento das atividades nos diversos setores dessa unidade permitiam e favoreciam atitudes violentas por parte das chefias, de modo que em algumas ocasiões chegava-se a concluir que, mesmo se um chefe fosse substituído por outro, o assédio continuaria acontecendo.

Essa compreensão sobre a gênese do assédio levou-nos a concluir que seria necessário intervir sobre as condições e a organização do trabalho, em especial, em como se davam as relações. Além disso, outra urgência era o sofrimento dos trabalhadores que vivenciaram o assédio diretamente e que, naquele momento, demandavam apoio psicológico.

\section{Assistência psicológica individual, mas não individualizante}

As situações de assédio já haviam deixado suas marcas. Aquelas pessoas passaram por situações geradoras de sofrimento psíquico, e uma demanda concreta que se apresentava era a de atenção psicoterapêutica. Oferecemos atividades terapêuticas em grupo baseados na experiência dos serviços públicos de saúde do trabalhador, que organizam grupos formativo-terapêuticos com vistas a: lidar com as repercussões psicológicas; construir formas de lidar com o sofrimento decorrente da situação vivida e suas repercussões; e construir formas de enfrentamento coletivas e individuais ${ }^{23}$. Entretanto, os trabalhadores vítimas da violência solicitaram que fossem assistidos individualmente por psicólogos. Assim, disponibilizamos atendimento clínico individual com participantes do projeto, sem perder de vista as dimensões de prevenção e promoção que integram a prática de atenção integral à saúde do trabalhador ${ }^{23}$. Essa ação deu-se em convergência e complementaridade com as discussões acerca das formas de organização do trabalho.

Essa formatação mostrou-se importante para assegurar a integralidade das ações. Nesse processo, estávamos atentos às potencialidades do atendimento psicológico individual inserido num contexto ampliado. Daí o entendimento de que se tratava de uma assistência individual, mas não individualizante; ou seja, disponibilizamos uma modalidade de assistência considerando a singularidade que caracteriza o sofrimento de cada trabalhador, sem desvincular os fatores desencadeantes desse sofrimento do contexto coletivo de trabalho no qual emergiram. Os atendimentos individuais foram complementares a todas as demais articulações do projeto. A compreensão da qual partimos não está relacionada a uma psicologia clínica que circunscreve as questões e os problemas à esfera individual, "recuperando" e adaptando os indivíduos para o trabalho ${ }^{24}$. O sofrimento no trabalho se expressa de forma individual, mas suas causas não serão encontradas nem sanadas individualmente. São as condições, as formas de organização, os processos de trabalho desenvolvidos que produzem sofrimento, e a violência do assédio vivenciada e relatada ilustrava bem isso.

Resgatamos uma clínica psicológica, social, ampliada ou situada ${ }^{24,25}$, diretamente articulada ao contexto de vida, precisamente ao de trabalho, e promovida como estratégia de assistência individual, mas integrada a um projeto de intervenção cujo horizonte, pelo ponto de partida e pelos desdobramentos, apontava para uma ação coletiva e política, com vistas a reverter ou, ao menos, resistir a formas de organização do trabalho que atentam contra a integridade do trabalhador no serviço público. Foi essa a compreensão que norteou os atendimentos individuais.

Análise do trabalho para transformá-lo: precarização e terceirização do ponto de vista dos trabalhadores

Considerando que as ações de prevenção dos problemas de saúde têm maior alcance resolutivo mediante a mudança das condições e da organização do trabalho, pretendíamos construir um diagnóstico das condições de alguns setores da Unidade de Manutenção para compreender, juntamente com os trabalhadores, os mecanismos que permitiram a eclosão de situações de violência. Nossa intenção era realizar um levantamento das condições e das atividades de trabalho. Buscaríamos algo próximo ao mapeamento de riscos proposto pelo Modelo Operário Italiano ${ }^{27}$, isto é,

[...] olhar o trabalho e os processos organizativos a partir do ponto de vista dos trabalhadores, mostrando situações difíceis de serem vividas, estratégias e táticas criadas e utilizadas para com elas $\operatorname{lidar}^{26}$. (p. 44)

De partida, fomos surpreendidos ao tomar conhecimento de um diagnóstico do trabalho bastante completo, realizado por um grupo composto por trabalhadores dos diversos setores da própria Unidade de Manutenção, que aqui será denominado de "coletivo". Esse levantamento foi construído por meio de visitas in loco a todas as seções da unidade e consultas a seus trabalhadores. O relatório final descreve a organização do processo de trabalho e as mudanças em termos de atribuições e número de trabalhadores de cada setor no decorrer do tempo, mapeando as dificuldades e os problemas enfrentados pelos setores e apresentando sugestões de melhorias. No relatório, são sugeridos remanejamentos e acordos cotidianos, adequações sanitárias, revisão de processos gerenciais, de planos de 
carreira e modernização de infraestrutura. São identificadas ainda as mudanças mais recentes advindas do processo de precarização pelo qual passa a universidade, bem como seus impactos no trabalho. As sugestões são acompanhadas de justificativas de natureza econômica (minimizar custos) e técnico-operacionais (melhoria nas relações e processos de trabalho). Esse diagnóstico apresenta um panorama dos efeitos da terceirização do ponto de vista dos trabalhadores da universidade, tema incomum nos estudos que focalizam a terceirização.

O "coletivo" foi formado por iniciativa da gerência da Unidade para promover encontros de confraternização. Entretanto, por iniciativa dos próprios participantes, o grupo assumiu o papel de canalizador dos anseios e demandas de todo o conjunto dos trabalhadores. Essa foi uma iniciativa autóctone, cujo resultado foi tão ou mais relevante do que o que nós poderíamos oferecer - um exercício de análise crítica, evidenciando que os trabalhadores são construtores e portadores de conhecimento sobre seu trabalho, suas condições e sua organização ${ }^{28}$. Além disso, surpreendeu-nos a capacidade reflexiva dos trabalhadores para conceber alternativas que melhorassem tais condições e a organização do trabalho, tanto no que toca à saúde como no que toca à qualidade do serviço prestado e à economia de recursos. A construção deste saber coletivo foi possível pois muitos trabalhadores estão alocados nessa unidade há muitos anos, o que facilitou a construção e o aprofundamento do conhecimento sobre o trabalho. Uma das grandes ameaças da rotatividade de trabalhadores é a perda das condições materiais que permitem essa construção: a familiaridade e a experiência no trabalho, bem como as conversas cotidianas entre os colegas, condição que se consegue apenas ao longo de anos de trabalho ${ }^{29}$. Diante de tão rico material, foi imperativo repensar nosso papel de assessores dos trabalhadores naquele momento.

Os caminhos trilhados nesta intervenção seguiram o fluxo dos acontecimentos que envolviam a relação prévia entre gerência e trabalhadores, marcada pela tensão devida à denúncia dos casos de assédio e ao progressivo desmonte da Unidade de Manutenção. Nesse contexto, participamos de duas reuniões em que os dados do diagnóstico foram apresentados e discutidos: uma primeira exclusivamente com o grupo que o elaborou e uma segunda na qual o grupo discutiu encaminhamentos do diagnóstico com um representante da gerência da unidade. Na primeira reunião, enfatizamos alguns aspectos levantados pelo diagnóstico e discutimos encaminhamentos para efetivar mudanças no trabalho. A segunda reunião foi decisiva, pois redefiniu os passos possíveis da intervenção: discutiu-se o diagnóstico elaborado pelo "coletivo" e, com base nele, a pauta de reivindicações composta por itens visando melhorias nas condições de trabalho, bem como a contribuição que o "grupo acadêmico" poderia oferecer nesse processo. Entretanto, no decorrer da reunião, o representante da gerência explicitou que não era cabível falar em projeto de intervenção conjunta, já que o trabalho que se pretendia transformar iria, na verdade, desaparecer. Foi a primeira vez, depois de anos, que os trabalhadores da Unidade de Manutenção ouviram que o seu trabalho, tal qual existente até aquele momento, deixaria de existir. Indícios de desmantelamento dos setores responsáveis pela manutenção sempre existiram, e a ameaça desse desmonte sempre foi uma fonte de sofrimento e apreensão para todos os trabalhadores. Entretanto, a gerência nunca explicitara tal intenção.

Tal fato exigiu a redefinição das formas de enfrentamento - e, consequentemente, desse projeto - à política de desmonte da instituição. Não fazia mais sentido discutir como mudar um trabalho que iria desaparecer. Ao mesmo tempo, os trabalhadores eram tomados por um sentimento de desvalorização e de inutilidade que contrastava com as histórias de realizações de seus muitos anos de trabalho. Além disso, observou-se que a concepção da gerência sobre condições de trabalho adequadas era distinta da expressa pelo diagnóstico apresentado pelo "coletivo".

Também foi possível reconhecer que a concepção da gerência sobre como a psicologia poderia atuar no campo do trabalho era restrita às práticas na área de recursos humanos, no caso, oferecer treinamentos aos trabalhadores para assumirem novas funções. Essa etapa do projeto deixou claro que a intervenção no campo da Saúde do Trabalhador dá-se no espaço da política. Ela reitera que a intervenção depende da correlação de forças entre gerência e trabalhadores.

O desfecho dessa etapa reafirmou que resgatar a memória do trabalho seria importante para registrar os saberes desses trabalhadores e os da própria universidade, contribuindo com a resistência aos impactos psicossociais do desmonte.

\section{Memória e resistência: uma proposta possível e suas ressonâncias concretas}

Com o avanço das terceirizações, a atual política da universidade fragiliza a perspectiva de continuidade do trabalho de seus funcionários efetivos. A impossibilidade de realizar suas atividades e de dar continuidade à sua história coletiva traz sofrimento aos trabalhadores. O desmonte é o passo anterior à terceirização e, por isso, os trabalhadores amargam escassez orçamentária, diminuição do quadro de funcionários do setor, maquinário em más condições e desvalorizações das mais variadas formas. Além disso, o trabalho bem realizado e o conhecimento envolvido 
são invisibilizados. Outro aspecto é a possibilidade de saber dos bastidores do processo de terceirização: os efetivos são "encostados", desvalorizados, convidados a pedir demissão ou realocados em outras áreas e funções até o desmantelamento completo da Unidade. Dessa forma, a justificativa para a terceirização é forjada, promovendo este tipo de vínculo como único, supostamente mais produtivo e mais adequado à modernização da universidade.

Para enfrentar essa situação, propusemos um resgate da memória de trabalho como resistência à perspectiva de fechamento da Unidade. Entendemos que tal ação seria importante para contrapor as repercussões negativas para a identidade e a saúde mental dos trabalhadores. Tal recurso tinha se demonstrado útil em reuniões com os trabalhadores de um dos setores da Unidade de Manutenção, nas quais fizemos longas conversas a partir de fotos antigas que registravam os trabalhos realizados com orgulho, os momentos de descontração e os companheiros. De fato, espontaneamente, foram os próprios trabalhadores desse setor que trouxeram fotos que haviam tirado em diversos lugares da universidade e em diferentes épocas, o que motivou o "grupo acadêmico" a sugerir que se trabalhasse com fotos.

Essa ação teve papel central em nossa intervenção, a qual pode ser fundamentada em Walter Benjamin ${ }^{30}$, que reconhece o caráter potencialmente revolucionário da memória proletária. A historiografia oficial ressalta as afinidades entre o que passou e o tempo presente, orienta-se pela ideia de progresso, e assim justifica a versão dos vencedores e sua dominação. Em sentido contrário, a construção narrativa a partir da memória popular pode revelar fissuras, lacunas no discurso dominante, promessas não cumpridas e que podem servir de herança para as futuras gerações.

Segundo Bosi ${ }^{31}$, a memória não é mera restituição de um conteúdo dominado e guardado pelo indivíduo, como se este fosse uma unidade de armazenamento informacional. Trata-se de trabalho do sujeito sobre sua experiência pregressa, aquilo que viveu em sua comunidade.

Na maior parte das vezes, lembrar não é reviver, mas
refazer, reconstruir, repensar, com imagens e ideias
de hoje, as experiências do passado. A memória não
é sonho, é trabalho. [...] O simples fato de lembrar
o passado, no presente, exclui a identidade entre as
imagens de um e de outro, e propõe a sua diferença
em termos de ponto de vista ${ }^{32}$. (p. 55)

Esse trabalho da memória é, em si, um ato de resistência. Benjamin ${ }^{30}$ o equipara ao ofício do artesão, avesso, portanto, ao trabalho fabril. É também, segundo Bosi ${ }^{32}$, resistência ao esquecimento produzido pela sociedade de consumo, que torna nossa relação com as pessoas, com os espaços e com os objetos sempre rápida, passageira, análoga à relação que temos com as mercadorias.

O esquecimento é também frequentemente produzido enquanto estratégia de dominação pelo capital, seja de forma deliberada e planejada por governos, seja pelas organizações. Frequentemente, nos processos de mudança organizacional (de terceirizações, por exemplo), apagam-se os rastros do que aconteceu, as marcas de antigos trabalhadores que ocupavam aquele lugar e que foram desligados ou se aposentaram. O esforço produzido procura fazer com que tudo se passe como um começar do nada. Retomar as lembranças dos trabalhadores na Unidade serviu aqui como resistência a esse processo imposto pela gestão do campus.

Nossa ideia foi produzir discussões que permitissem a reflexão sobre o próprio trabalho, a recordação de histórias que construíram os percursos daqueles trabalhadores e que, ao mesmo tempo, pudessem ser registradas com o objetivo de se produzir um material que servisse simultaneamente para fomentar as discussões, levar a outras pessoas as experiências relatadas e constituir um arquivo sobre a vida desses trabalhadores invisibilizados na universidade. Nesse sentido, o resgate da memória se deu também como uma atividade de cuidado, principalmente pela valorização das situações vividas.

O fato é que a situação do desmonte em si mesma impulsionou uma longa greve que coincidiu com esse momento do projeto, o que inviabilizou a proposta de registrar imagens dos trabalhadores. A condição de vulnerabilidade na qual se encontravam criou justificáveis temores quanto a perseguições e retaliações. Combinou-se então que a equipe de pesquisadores reuniria os diversos relatos obtidos no trabalho de campo e produziria um material escrito sem identificar os trabalhadores. Esse material, composto por histórias dos trabalhadores, relatos do projeto e por reflexões dos componentes do "grupo acadêmico", será apresentado aos trabalhadores como devolutiva da pesquisa-intervenção participativa.

\section{Considerações finais}

Conforme indicado no início, esta pesquisa-intervenção participativa aconteceu por meio da construção de conhecimentos coletivos, com o compromisso ético-político de, na perspectiva libertadora de Paulo Freire, intervir como facilitadores do conhecimento da realidade por um grupo de trabalhadores com vistas ao enfrentamento dos problemas que se apresentaram.

Partimos de uma demanda concreta, e a formação do "grupo do projeto" possibilitou a coexistência em um espaço favorável para a análise conjunta 
dos problemas enfrentados e para a reflexão que guiaria as ações. As situações de assédio demandaram o desenvolvimento de atividades preventivas e formativo-terapêuticas.

Dado que não seria possível promover mudanças nas condições e na organização do trabalho, pois a Unidade de Manutenção como um todo estava em vias de desaparecer, a opção foi fortalecer o coletivo de trabalho para enfrentar essa situação, o que se buscou a partir de uma pista fornecida pelos próprios trabalhadores: seu interesse espontâneo em contar como era seu trabalho em outros tempos por isso, a vinculação entre memória e resistência. Buscou-se atender uma necessidade latente de cuidado: o reconhecimento da história de cada um dos trabalhadores que literalmente construíram aquela universidade e foram também responsáveis por mantê-la num patamar de excelência.

Várias foram as estratégias pensadas coletivamente para concretizar as ações pretendidas e modificá-las de acordo com as circunstâncias de cada fase do projeto. Nossa proposta de análise do trabalho foi surpreendida por outra análise, feita pelos próprios trabalhadores. Como se espera em uma pesquisa-intervenção participativa, muitas ideias de viabilizar as propostas surgiram e nem todas foram viáveis, pois trata-se de atividade que se dá no campo da correlação de forças entre trabalhadores e corpo gerencial. Não se trata, portanto, de aplicar técnicas num terreno asséptico.

A principal conclusão que tiramos dessa experiência de pesquisa-intervenção participativa é que a escolha do lugar a partir do qual se faz a intervenção é vital para a sua realização e para o alcance que ela pode ter. Estivemos em campo como pesquisadores e acadêmicos, partindo de pressupostos teórico-metodológicos que sustentam a importância da participação dos trabalhadores nos processos de intervenção. Mas chegamos lá pela via da assessoria sindical e não pelas mãos da gerência, cujas demandas configurariam nossas ações de modo completamente diferente e as submeteriam a um quadro de restrições distinto.

Nossa opção foi legitimar o lugar institucional dos trabalhadores organizados e, compreendendo as relações cotidianas de trabalho como um campo de disputas, tentar aprimorar em conjunto com os trabalhadores suas ferramentas para esse enfrentamento. Nosso trabalho, portanto, não foi de mediação, mas um esforço de, com os trabalhadores, pensar o trabalho para além dos constrangimentos próprios da racionalidade da gestão (cujo horizonte de possibilidades é sempre muito restrito) e fortalecer sua posição, como trabalhadores organizados, no enfrentamento de processos conflituosos que compreendem relações desiguais de poder.

Os efeitos dessa pesquisa-intervenção se deram em via de mão dupla. A cada encontro, as propostas se desenhavam de acordo com os relatos e experiências junto aos trabalhadores, resultando de construções coletivas articuladoras de conhecimentos técnicos e saberes práticos de ambos os lados, envolvendo aprendizagens e reconhecimentos mútuos.

Nossa presença em campo, a constituição de uma comunidade ampliada de pesquisa e intervenção (o "grupo do projeto") e as discussões suscitadas tiveram como efeito fortalecer os trabalhadores em sua luta. Mesmo diante das diversas tentativas por parte da gestão da universidade de descaracterizar as reivindicações dos trabalhadores, o parecer feito por alguns de nós, as conversas realizadas a cada momento para decidir táticas de ação e a mobilização que isso gerou tiveram sua importância.

Esse processo foi longo, estimulante e cheio de desafios, uma atividade mergulhada na vida pulsante, com riscos reais, que exigia de todos nós envolvimento e capacidade para conviver com uma realidade que não se deixava apreender apenas com explicações, métodos e técnicas registrados nas páginas dos livros. Foi preciso conviver, ouvir, argumentar e contra-argumentar para construirmos entendimentos e saberes sobre o processo, os problemas e as alternativas de atuação e cuidado, considerando as condições políticas e as possibilidades técnicas. Isso só foi possível porque construímos relações horizontais - e não hierarquizadas - entre estudantes, trabalhadores da Unidade de Manutenção, professores e pesquisadores. Como bem disse um dos pesquisadores que participou do projeto, o grupo mostrou capacidade ímpar para aprender uns com os outros e, assim, construir conhecimento.

\section{Contribuições de autoria}

Todos os autores contribuíram igualmente no desenvolvimento do projeto e na elaboração e aprovação do texto publicado. 


\section{Referências}

1. Oliveira F, Esteves EG, Bernardo MH, Sato L. Psychologie sociale du travail: rencontres entre recherche et intervention. Bulletin de Psychologie. 2015;2(536):93-104.

2. Ribeiro MA, Oliveira F, Bernardo MH, Navarro VL. Práticas em psicologia social do trabalho: pesquisa e intervenção. In: Coutinho MC, Bernardo $\mathrm{MH}$, Sato L, editors. Psicologia social do trabalho. Petrópolis: Vozes; 2017. p. 103-26.

3. Chanlat JF. O gerencialismo e a ética do bem comum: a questão da motivação para o trabalho no serviço público. In: VII Congreso Internacional del CLAD sobre la reforma del Estado y de la administración pública; 2002; Lisboa, Portugal. Available from: https://goo.gl/ypUzFc

4. Bresser-Pereira LC. A reforma do Estado nos anos 90: lógica e mecanismos de controle. Cadernos MARE da Reforma do Estado. 1997;1:7-54.

5. Druck G. A terceirização na saúde pública: formas diversas de precarização no trabalho. Trab Educ Saúde. 2016;14(supl.1):15-43.

6. Druck G. Terceirização no serviço público: múltiplas formas de precarização do trabalho. In: Navarro VL, Lourenço EAZ, editors. O avesso do trabalho IV: terceirização, precarização e adoecimento no mundo do trabalho. São Paulo: Outras Expressões; 2017. p. 50-87.

7. Chauí M. A universidade operacional. Folha de São Paulo. 1999 May 9; Caderno Mais!, p. 3.

8. Chauí M. Escritos sobre universidade. São Paulo: Unesp; 2001.

9. Chauí M. A universidade pública sob nova perspectiva. Rev Bras Educ. 2003;24(3):5-15.

10. DIEESE. O processo de terceirização e seus efeitos sobre os trabalhadores. In: DIEESE. Relações e condições de trabalho no Brasil. São Paulo: DIEESE; 2008 [cited 2018 Jul 25]. p. 73-147. Available from: www.dieese.org.br/livro/2008/ relacoesCondicoesTrabalhoBrasil.pdf

11. Barros SP. Biopolítica, neoliberalismo e vulnerabilidade: os trabalhadores terceirizados na universidade pública [thesis] São Paulo (SP): Universidade de São Paulo; 2015.

12. Coutinho MC, Diogo MF, Joaquim EP, Borges RCP. O trabalho de manutenção em uma prefeitura universitária: entre dificuldades e realizações. Psicol Cienc Prof. 2011;31(1):96-109.

13. Granzotto TM. A implementação de ações neoliberais nas universidades públicas. Serv Soc \& Saúde. 2011;10(12):171-96.

14. Franco T, Druck G, Seligmann-Silva E. As novas relações de trabalho, o desgaste mental do trabalhador e os transtornos mentais do trabalho precarizado. Rev Bras Saúde Ocup. 2010;35(22):229-48.

15. Brandão CR. Pesquisar-participar. In: Brandão CR. Pesquisa participante. São Paulo: Brasiliense; 1985. p. 9-16.
16. Freire P. Criando métodos de pesquisa alternativa. In: Brandão CR, editor. Pesquisa Participante. São Paulo: Brasiliense; 1985. p. 34-41.

17. Pais JM. O cotidiano e a prática artesanal de pesquisa. Rev Bras Sociologia. 2013;1(1):105-28.

18. Neves MY, Muniz HP, Silva EF, Costa JD, Brito J, Athayde M. Saúde, gênero e trabalho nas escolas públicas: potencialidades e desafios de uma experiência com o dispositivo "Comunidade Ampliada de Pesquisa e Intervenção”. Laboreal. 2015;11(1):53-68.

19. Botechia F, Athayde M. Um regime de produção de saberes sobre o trabalhar e suas relações: a Comunidade Ampliada de Pesquisa. In: Encontro Nacional da Associação Brasileira de Psicologia Social; 2007; Rio de Janeiro, Brasil.

20. Becker H. Métodos de pesquisa em ciências sociais. São Paulo: Hucitec; 1999.

21. Coulon A. A escola de Chicago. Campinas: Papirus; 1995.

22. Vieira CEC, Lima FPA, Lima MEA. E se o assédio não fosse moral? Perspectivas de análise de conflitos interpessoais em situações de trabalho. Rev Bras Saúde Ocup. 2012;37(126):256-68.

23. Sato L, Lacaz FAC, Bernardo MH. Psicologia e saúde do trabalhador: práticas e investigações na Saúde Pública de São Paulo. Estud Psicol (Natal). 2006;11(3):281-8.

24. Sato L, Schmidt MLS. Psicologia do Trabalho e Psicologia Clínica: um ensaio de articulação focalizando o desemprego. Estud Psicol (Natal). 2004;9(2):365-71.

25. Schmidt MLS. Clínica psicológica, trabalho e desemprego: considerações teóricas. Cad Psicol Soc Trab. 2004;7:1-10.

26. Sato L. Psicologia, saúde e trabalho: distintas construções dos objetos "trabalho" e “organizações”. In: Conselho Federal de Psicologia, editor. Psicologia crítica do trabalho na sociedade contemporânea. Brasília: CFP; 2010.

27. Oddone I et al. Ambiente de trabalho: a luta dos trabalhadores pela saúde. São Paulo: Hucitec; 1986.

28. Dejours C. Por um novo conceito de saúde. Rev Bras Saúde Ocup. 1986;14(54):7-11.

29. Sato L. A representação social do trabalho penoso. In: Spink MJP, editor. O conhecimento no cotidiano: as representações sociais na perspectiva da psicologia social. São Paulo: Brasiliense; 1993. p. 188-211.

30. Benjamin W. O narrador: considerações sobre a obra de Nicolai Leskov. In: Benjamin W. Obras escolhidas: magia e técnica, arte e política. 7 th ed. São Paulo: Brasiliense; 1994. p. 197-221.

31. Bosi E. Memória e sociedade: lembranças de velhos. 3rd ed. São Paulo: Companhia das Letras; 1994.

32. Bosi E. O tempo vivo da memória: ensaios de Psicologia Social. São Paulo: Ateliê; 2003. 
No manuscrito: "Pesquisa-intervenção participativa com trabalhadores da Unidade de Manutenção de uma universidade pública: precarização, memória e resistência", com número de DOI: 10.1590/2317-6369000012518, publicado no periódico Revista Brasileira de Saúde Ocupacional, 43(supl 1):e3s, na página 7/8, após "Contribuições de autoria" inclua-se:

\section{Agradecimentos}

Além dos autores do presente artigo, também fizeram parte da equipe do projeto: Arthur Gobatti Mota, Bárbara Ribeiro de Souza Dias, Camila Danielle dos Santos, Catarina da Silva Vilar, Gianlucca Vergian Dalenogare, Liliane Miyuki Uratsuka, Lucas Amaral Saporiti e Richard de Oliveira. 